
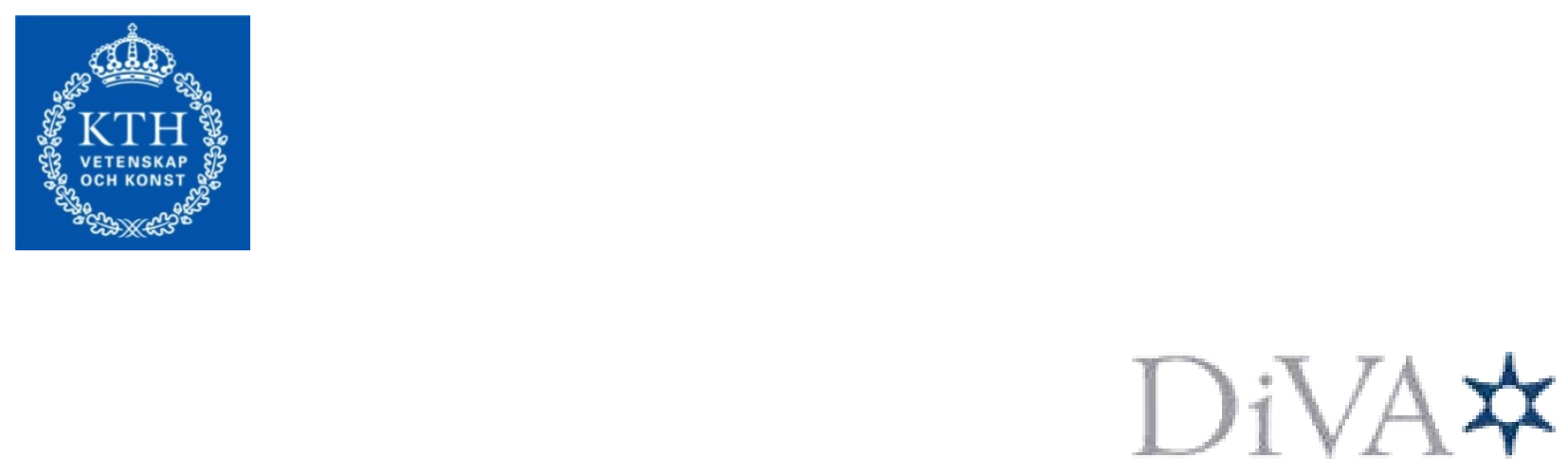

http://kth.diva-portal.org

This is an author produced version of a paper published in IEEE Transactions on Industry Applications. This paper has been peer-reviewed but does not include the final publisher proof-corrections or proceedings pagination.

(C) 2013 IEEE. Personal use of this material is permitted. Permission from IEEE must be obtained for all other uses, in any current or future media, including reprinting/republishing this material for advertising or promotional purposes, creating new collective works, for resale or redistribution to servers or lists, or reuse of any copyrighted component of this work in other works.

Citation for the published paper:

Rabkowski, J., D.Peftitsis, H.P. Nee.

Design Steps Towards a 40-kVA SiC JFET Inverter With Natural-Convection Cooling and an Efficiency Exceeding 99.5\%

IEEE Transactions on Industry Applications, 2013.

Access to the published version may require subscription.

Published with permission from: IEEE 


\title{
Design Steps Towards a 40-kVA SiC JFET Inverter With Natural-Convection Cooling and an Efficiency Exceeding $99.5 \%$
}

\author{
Jacek Rabkowski, Dimosthenis Peftitsis, and Hans-Peter Nee \\ Electrical Energy Conversion (E2C) Lab \\ School of Electrical Engineering, \\ KTH Royal Institute of Technology, \\ Teknikringen 33, SE-10044, Stockholm, \\ Sweden \\ rabkow@kth.se
}

\begin{abstract}
This paper describes the concept, the design, the construction, and experimental investigation of a $40 \mathrm{kVA}$ inverter with silicon carbide junction field effect transistors (JFETs). The inverter was designed to reach an efficiency exceeding $99.5 \%$. The size of the heatsink is significantly reduced in comparison to silicon insulated-gate bipolar transistor designs, and the high efficiency makes it possible to use free-convection cooling. This could potentially increase the reliability compared to solutions with fans. A very low conduction loss has been achieved by parallel connecting ten 85 $\mathrm{m} \Omega$ normally-on JFETs in each switch position. A special gatedrive solution was applied forcing the transistors to switch very fast (approx. $10 \mathrm{kV} / \mu \mathrm{s}$ ) resulting in very low switching losses. As the output power is almost equal to the input power a special effort was done to precisely determine the amount of semiconductor power losses via comparative thermal measurements. A detailed analysis of the measurements shows that the efficiency of the inverter is close to $99.7 \%$ at $40 \mathrm{kVA}$.
\end{abstract}

Index Terms-Silicon carbide, DC/AC inverters, parallelconnection, high-efficiency, efficiency measurements

\section{INTRODUCTION}

State-of-the-art three-phase switch-mode inverters are widely applied, mainly as supplies to various types of electric motors, from induction machines to permanent magnet ones [1]-[6]. Doubtless, in most cases currently available silicon power semiconductors meet the application requirements regarding efficiency, reliability, and cost. Even if siliconbased insulated-gate bipolar transistors (IGBTs) have reached a significant degree of maturity, slight improvements are still anticipated. One example is the development of hightemperature $\left(\mathrm{Tj}>175^{\circ} \mathrm{C}\right)$ IGBT modules for hybrid electric vehicles [7]-[8]. With this in mind, the question arises if there is space for the introduction of silicon carbide ( $\mathrm{SiC}$ ) threephase inverters for motor drives [9].

During the last decade $\mathrm{SiC}$ power devices have gained a large interest in the power semiconductor field due to their superior performance compared to the state-of-the-art silicon (Si) counterparts. This was enabled not only due to the dramatic improvement of the $\mathrm{SiC}$ material, but also due to the excellent research and development efforts than have been made both on the design and the fabrication of $\mathrm{SiC}$ power devices. Today, $\mathrm{SiC}$ devices have reached a degree of maturity where they could be considered as an alternative to the $\mathrm{Si}$ power devices and they could be employed even in commercial power electronics converters. Such applications could be photovoltaic inverters [10]-[11], converters for hybrid electric cars [12]-[16], and in the future high-power applications (e.g. high-voltage dc transmission systems) [17]. In a longer perspective, also standard industrial drives could be equipped with $\mathrm{SiC}$-based power converters in cases where the requirements on efficiency, compactness, or temperature are particularly challenging. However, the cost and the low current and voltage ratings constitute two factors which limit the range of the targeted applications of $\mathrm{SiC}$ devices. The cost, on the one hand, reduces monotonically due to the improvements in quality of the $\mathrm{SiC}$ material and increased yields. Higher current ratings, on the other hand, can be reached by parallel connection of discrete $\mathrm{SiC}$ devices [18][19], or parallel-connection of chips in a multi-chip module [20]-[21].

Currently, three types of $\mathrm{SiC}$ power transistors have been released: the SiC Junction Field Effect Transistor (JFET), the Bipolar Junction Transistor (BJT), and the Metal-OxideSemiconductor Field Effect Transistor (MOSFET). Due to their early development stage, almost all of them suffer from various issues that must be solved in order to come up with reliable and robust $\mathrm{SiC}$ converters. The normally-on problem for (the best) SiC JFETs [22], the low current gains for SiC BJTs [23], and the stability of the oxide layer of the SiC MOSFET [24] count as such problems.

Regardless of the type of the SiC device and looking from a systems perspective, there are basically three possible design directions when $\mathrm{SiC}$ devices are employed: high switching 
frequency, high temperature, and high efficiency. An attempt to illustrate how the design can be optimized is shown in Fig.1. Each of these directions can be followed based on the design requirements, and a number of interesting examples can be found in the literature [9]-[12],[25]-[27]. Doubtless, the high efficiency direction is also available with, for instance, super-junction Silicon MOSFETs but more chip area (or parallel-connected devices) is required. This paper presents the design steps towards a $40 \mathrm{kVA}$ three-phase $\mathrm{SiC}$ inverter $(3 \times 400 \mathrm{~V}$ output) for low voltage applications. Ten parallelconnected normally-on SiC JFETs in each switch position are employed. The design goal for this inverter deals with high efficiency (>99.5\%) and thus, minimization of power losses is necessary.

The efficiency target dictates that the total losses of the $40 \mathrm{kVA}$ inverter should be lower than $200 \mathrm{~W}$. Due to the remarkably low loss value, the need for cooling equipment is exceptionally low. Without any deeper analysis it is likely that natural-convection cooling without a fan is fully sufficient. Thus, the reduced size of the cooling system is not the only benefit with the proposed design, but also the remarkably low levels of acoustic noise and the, potentially, increased reliability due to the elimination of the fan.

In Section II preliminary design considerations for the 40 kVA three-phase $\mathrm{SiC}$ inverter are presented. The next section shows the gate driver design which is a vital part of the inverter in order to reach as low switching losses as possible. The construction steps of the inverter are summarized in Section IV, while Section V presents the experimental results. Both electrical and thermal measurements are presented in this section. Finally, a discussion of the results and a short conclusion are given in Sections VI and VII respectively.

\section{DESIGN PROCESS}

As already mentioned, there are three possible design directions when $\mathrm{SiC}$ devices are employed in a power electronic converter. This can be illustrated by means of an efficiency/frequency/temperature triangle, as can be seen in Fig. 1, which shows all possible cases placed in different areas. Note that each design direction for $\mathrm{SiC}$ devices lead to an increase of the inverter compactness: less voluminous passive elements or a smaller heatsink. Besides the solution with integrated sinus filter [36], high frequencies are usually not necessary for inverters as, for instance, the inductance of an electric motor is sufficiently large to filter the current, already at moderate frequencies. High temperatures and high efficiencies are, however, often sought. Among these two alternatives the high-efficiency approach is the most straightforward choice since no special packaging technology is necessary. Additionally, there are no special hightemperature requirements for auxiliary components such as capacitors and logic circuits. These are the reasons for why the high-efficiency approach was chosen for the present threephase inverter.

In order to reach a high efficiency it is necessary to study on-state losses, switching losses, and driver losses and optimize them. The project goal was to achieve an efficiency exceeding $99.5 \%$ of the $40 \mathrm{kVA}$ three-phase inverter (Fig. 2a) using available $\mathrm{SiC}$ devices. Calculations for the output

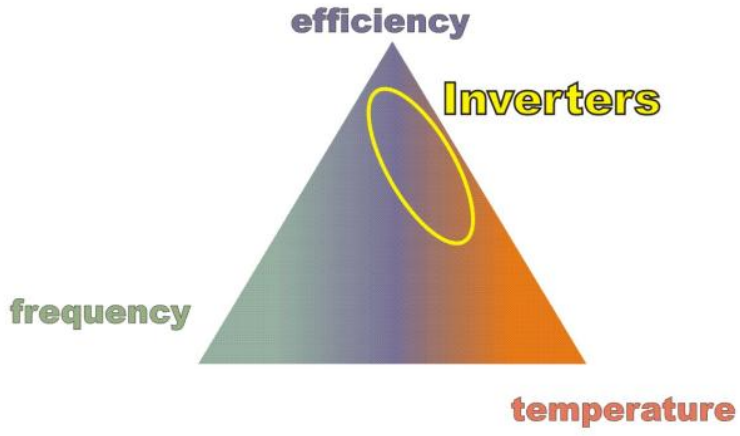

Fig. 1 The inverters inside the triangle of three design directions with the SiC devices

current and voltages have been performed assuming a rated power of $40 \mathrm{kVA}$. It is shown that the expected phase current equals 58 A RMS (82 A peak) at the rated power when a typical output voltage of $400 \mathrm{~V}$ RMS is considered. Since none of the currently available $\mathrm{SiC}$ transistors (first months of 2011) was capable of conducting such high currents, the only solution was to parallel-connect several of them. Thus, a higher current capability could be achieved, and at the same time the on-state power losses could be reduced. A study has been conducted in order to find the optimal solution and to determine the type and the required number of parallelconnected devices which satisfy the expectation of low onstate power losses.

Basically, the conclusion is that all types of available $\mathrm{SiC}$ devices show positive temperature coefficient and parallel connection is possible [18],[19]. Then, with the use of suitable gate drivers similar switching speeds could be reached for all transistors [28]-[32]. More specifically, both normally-off JFETs and BJTs require more driving power while MOSFETs suffer from oxide layer and transconductance problems [24], [33]. In spite of the normally-on characteristics, often

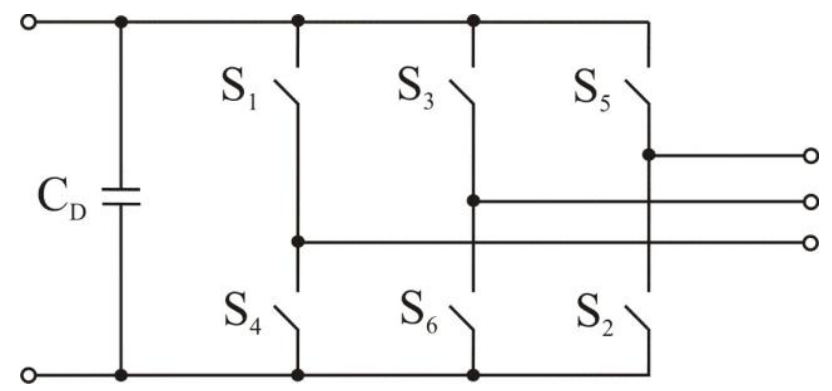

(a)

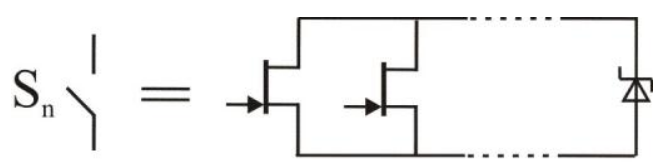

JFET x 10

(b)

Fig. 2 (a) Schematic of the three-phase SiC inverter and (b) detailed circuit of the single switch position 
recognized as the major drawback, SiC JFETs from Semisouth Laboratories Inc. (SJDP120R085, $85 \mathrm{~m} \Omega @ 25^{\circ} \mathrm{C}, 1200 \mathrm{~V}$ ) were finally chosen for this project. The main reasons supporting this choice were:

- low on-state resistance with the lowest dependence on temperature rise among different SiC JFET designs.

- experience with drive units and parallel connection of these transistors.

- reasonable price and availability of the required number of devices in a short time.

- $\quad$ possibility to use the JFET as an anti-parallel diode when the current is negative (lower voltage drop than a Schottky diode).

Even though the normally-ON nature might be a drawback for many power electronics applications, there are a few solutions to this problem which have been recently proposed. The majority of these solutions to the normally-ON problem deals with clearing the short-circuit current when the JFETs are subjected to the dc-link voltage, but the power to the gate during the steady-state operation is supplied externally [37][43]. A complete circuit solution to the normally-ON problem of the SiC JFETs is shown in [44]. In this case, the proposed circuit is able to clear the short-circuit current within a few tens of $\mu$ s on the one hand, while on the other hand, it utilizes the blocking voltage of the JFETs in order to continuously supply the steady-state voltage to the gate-drive circuit.

The on-state losses are decreasing when the number of parallel-connected devices and the total chip area is increasing (Fig.3b). The distribution of the switching losses among the parallel-connected discrete JFETs is a non-trivial issue, which has been discussed more in [19]. In fact, they are expected to be increased due to the parallel-connection of the device capacitances and the parasitic inductances of the inverter layout. On the other hand, both problems may be minimized with suitable gate driver and power circuit designs and thus the negative impact on the switching losses can be reduced. Finally, with a high number of parallel-connected JFETs the driver design becomes more complicated and the associated driver power is also increased.

It was, therefore, decided to employ 10 parallel-connected normally-on SiC JFETs in each switch position of the inverter (Fig. 2b). In this case, a good agreement between low on-state losses and system complexity is reached. The on-state resistance per switch position is slightly higher than $10 \mathrm{~m} \Omega$ as can be seen from characteristics in Figure 3. The total chip size of the single device is $4.5 \mathrm{~mm}^{2}$ which gives a total of 45 $\mathrm{mm}^{2}$ in each switch position [34]. Hence, the current density equals $180 \mathrm{~A} / \mathrm{cm}^{2}$ (peak).

As normally-on JFETs offer a reverse conduction capability it was also decided to apply only a single $30 \mathrm{~A} \mathrm{SiC}$ Schottky diode (SDP30S120, Semisouth Laboratories Inc.) (see Fig. 2b). Thanks to the remarkably low on-state resistance of the ten parallel-connected JFETs, the voltage drop across the transistors $(\sim 0.8 \mathrm{~V}$ at nominal current) is lower than the threshold voltage $(0.85 \mathrm{~V})$ of the $\mathrm{SiC}$ Schottky diode. Thus, this diode is operating only during short blanking-time periods

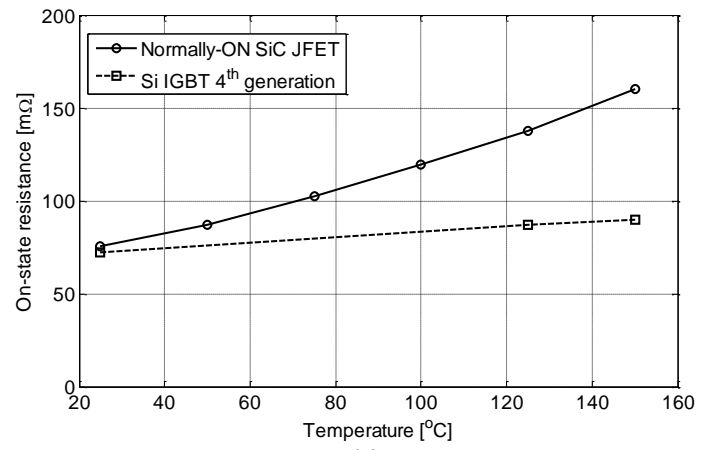

(a)

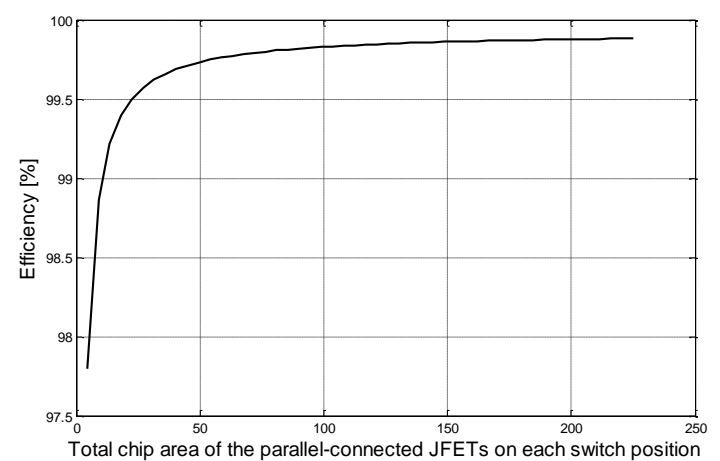

(b)

Fig. 3 Comparison of the on-state resistance versus junction temperature of the single SJDP120R085 and Si IGBT (Infineon

FP25R12W2T4_B11) (a) and efficiency vs. chip area of the parallelconnected JFETs

(fixed to $250 \mathrm{~ns}$ ). This means that the power losses of the inverter are not influenced by the power factor of the load, a fact which will be utilized later for determination of the losses. In addition, both good switching features and low switching frequency $(10 \mathrm{kHz})$ lead to very low switching losses in the $\mathrm{SiC}$ Schottky diodes. The overall power losses of the 6 diodes were assumed to be negligible and in the preliminary loss calculation only the 60 transistors were taken into account.

Assuming conduction of the JFETs in both directions (resistor-type switch) and an on-state resistance of approximately $10 \mathrm{~m} \Omega$ per switch position, the conduction power loss is slightly above $100 \mathrm{~W}$. With this value of conduction losses, an efficiency above $99.5 \%$ should be reachable considering the actual junction-to-case thermal resistance and provided that the heat sink is chosen with care. The data presented in Fig. 3 suggests that the junction temperature $T_{j}$ should be lower than $75^{\circ} \mathrm{C}$. An increase of the junction temperature would lead to a considerable increase in on-state power losses $\left(180 \mathrm{~W} @ \mathrm{Tj}>125^{\circ} \mathrm{C}\right)$, and the design criterion of $200 \mathrm{~W}$ total losses could not be fulfilled. All in all, besides an increased chip area, the junction temperature must be comparably low in order to obtain an efficiency exceeding $99.5 \%$, especially when an additional loss contribution, the switching losses, must be taken into account.

The switching process of the ten JFETs connected in parallel is a very complicated issue since the devices are in discrete packages [18],[19]. For simplicity, the switching losses were calculated using the same method as for a single 
transistor switching with a voltage slope of $10 \mathrm{kV} / \mu \mathrm{s}$. The estimated switching losses are approximately $38 \mathrm{~W}$ for the nominal conditions $(700 \mathrm{~V}, 82 \mathrm{~A}, 10 \mathrm{kHz})$. The accuracy of the predicted switching losses is not the most important aspect in the design process since the on-state losses are expected to be the dominant loss contribution $(\sim 70 \%)$. With the switching speeds used, $10 \mathrm{kHz}$ can actually be considered to be a comparably low switching frequency. Another remark regarding the losses is that total losses in the range of $140 \mathrm{~W}$ refer to $23.3 \mathrm{~W}$ per switch position, which implies only $2.33 \mathrm{~W}$ per transistor $\left(0.5 \mathrm{~W} / \mathrm{mm}^{2}\right)$. This number is obviously valid when symmetrical current sharing is achieved by good thermal coupling between parallel-connected devices. Furthermore, less than $1 \mathrm{~W} /$ transistor of switching losses are expected. This reduces the significance of the uniform switching problem. Even if a single or a small group of the transistors take the majority of the switching losses, the risk of thermal runaway is negligible as the maximum power dissipation is merely $114 \mathrm{~W}$. A more realistic scenario is a slight increase of in junction temperature and on-state resistance over the average value among the transistors, which in turn results in lower conduction losses.

Usually, $\mathrm{SiC}$ transistors are recognized as extremely expensive but the dramatic cost reduction during the last years has changed this picture. The total cost for the semiconductors (diodes and transistors) was approximately $1.5 \mathrm{kUSD}$ (37.5 $\mathrm{USD} / \mathrm{kW})$. According to the recommendations of the manufacturer, the current rating of the applied transistors is 27 $\mathrm{A}$ at $25^{\circ} \mathrm{C}$ or $17 \mathrm{~A}$ at $100^{\circ} \mathrm{C}$ and only 4 devices in parallel would be enough to carry nominal current. Obviously, this would cut the device cost almost by half (the cost for the $\mathrm{SiC}$ diodes would remain the same) but rise the conduction losses at least 2.5 times. Thus, the additional cost for reaching the very high efficiency with the increase of the transistors chip size is approximately $17.5 \mathrm{USD} / \mathrm{kW}$.

The final step in the design process was the selection of a suitable heatsink with respect to the expected power losses as well as the high number of discrete devices. The heatsink which fulfills mentioned above requirements for the room temperature is of the type $165 \mathrm{AB}$ (size $300 \times 300 \times 40 \mathrm{~mm}$, $\left.\mathrm{R}_{\mathrm{TH}}=0.22^{\circ} \mathrm{C} / \mathrm{W}\right)$.

\section{GATE DRIVE UNITS}

Driving ten parallel JFETs is a challenging task. It is not a trivial issue to obtain uniform switching conditions, especially if the devices are mounted in discrete TO-247 packages. In this project, extensive efforts have been made to ensure similar waveforms in all gate circuits of the ten parallelconnected transistors. Firstly, a state-of-the-art gate-driver circuit for the normally-on JFET has been employed [28]. This circuit can handle the spread in the pinch-off and breakdown voltages of the gates $(-19.5 \mathrm{~V}$ to $-28 \mathrm{~V})$, which is very important for achieving high-performance switching transitions. In order to limit this problem, the first attempt was to subdivide the devices into 6 groups with respect to the transistor parameters. In consequence, each switch position consists of ten JFETs with the closest breakdown voltages of the gates - a parameter that is easily measurable.
The next step in order to achieve close to uniform switching transitions was to select an appropriate driver arrangement. Assuming that the devices should be mounted in a row together with the single SiC diode (the same TO-247 package), the driver board width should be at least $220 \mathrm{~mm}$. The use of a common supply for all JFETs with a common source plate would result in undesirable currents between the board sections. Taking into account also the current rating of the driver components, as ICs, speed-up capacitors, resistors etc, finally, the solution with five sub-drivers was chosen (see Fig. 4). The driver board was divided into five identical sections, subdrivers, driving two JFETs from each single supply $\mathrm{V}_{\mathrm{S}}(30 \mathrm{~V})$. The design of the printed circuit board (PCB) was optimized in order to obtain simultaneous turn on/off of the diodes of the HCPL2611 optocouplers driven by the control signal originating from a digital signal processor (DSP) controller (TMS320F28335). Each JFET is served by a separate integrated circuit (IC) (IXDD614) and DRC network [19]. The final driver board (size $274 \times 46 \mathrm{~mm}$ ) can be seen alone in Fig. 4a and mounted on the devices in Fig. 5. Note, that the PCBs for the negative and positive switch positions were mirrored in order to mount through-hole parts on the outer side. The space between the boards is filled with dc capacitors in order to balance parasitic inductances of the copper busbars. The presented driver arrangement is suitable only for the discrete-device approach. However, a price for this is complexity and increased power consumption. In future

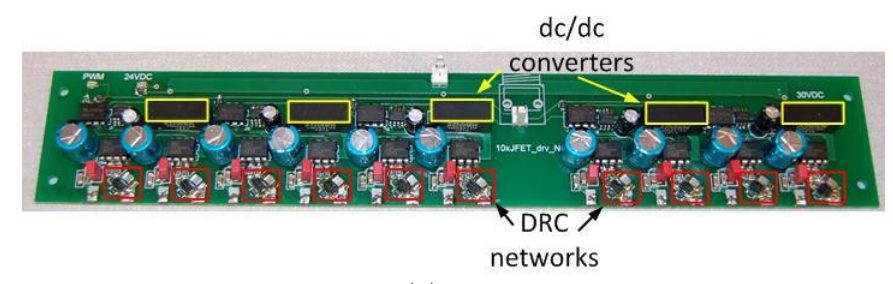

(a)

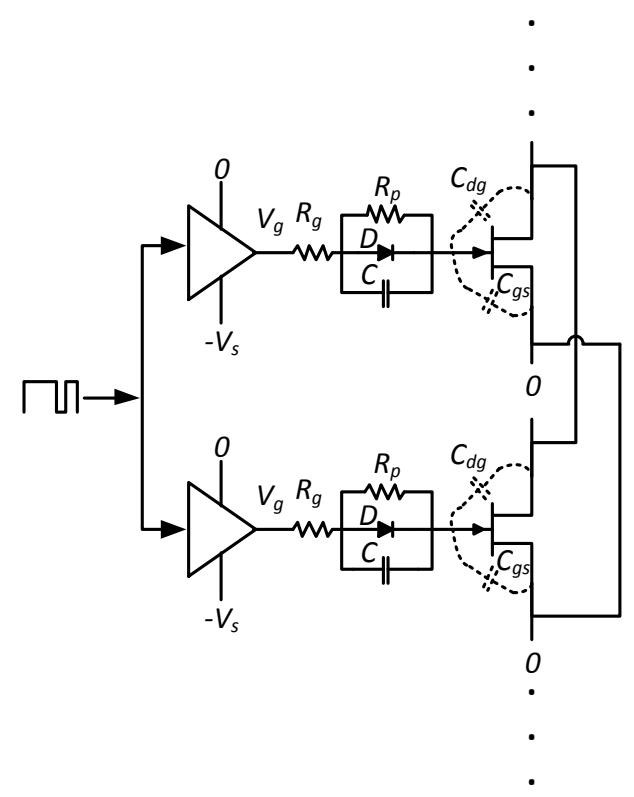

(b)

Fig. 4 Photograph (a) and schematics (b) of the sub-driver for two normally-on SiC JFETs 
designs for $\mathrm{SiC}$ modules these two factors will be optimized.

\section{CONSTRUCTION}

One of main design challenges of the SiC JFET inverter deals with the high number of power devices in TO-247 package which need to be mounted on the heatsink. In total 60 SiC JFETs and $6 \mathrm{SiC}$ Schottky diodes, i.e. 11 devices in each switch position, are required. This approach is far away from optimal for this power range due to parasitic inductances and capacitances influencing the switching process. The assembly of such a structure was found to be quite difficult. Doubtless, the best solution would be a power module as in [20], [21]. But the decisive advantage of the discrete approach in this project was the availability of the devices in short time and at a quite reasonable cost. Another positive aspect that can be mentioned is the more uniform heat spread than in the power module, where the heat source is more concentrated

The applied heatsink was chosen to meet requirements of thermal resistance and power dissipation $\left(\mathrm{R}_{\mathrm{TH}}=0.22{ }^{\circ} \mathrm{C} / \mathrm{W}\right.$, $200 \mathrm{~W})$. An important aspect was also the size of the mounting surface enabling placement of all 66 devices on the front side. The $30 \mathrm{~mm}$ long fins situated on the backside of the inverter were thought to be situated vertically improving natural convection of the heat. However, even if the data of the heatsink shows that it is capable of dissipating more than the expected $140 \mathrm{~W}$, it must also be kept in mind that the junction temperature rise should be kept lower than $50^{\circ} \mathrm{C}$. This is especially important since the partly quadratic temperature dependence shown in Fig. 3 might cause a problem with thermal runaway for higher temperature rises.

The switch position arrangement with eleven devices in a vertical row was chosen (see Figs. 5 and 6) from many possible solutions. The PCBs of the gate drivers are, therefore, also placed vertically and soldered directly to the appropriate transistors legs. Between the rows of the devices representing the upper and lower switches of the actual phase a three-layer busbar was applied. The copper sheets $(1 \mathrm{~mm})$ are separated from the heatsink and each other with insulation material. Moreover, the cross-section of the busbar was adjusted to improve the soldering process of the JFET legs. The overall shape of the busbar resembles a rotated capital letter $\mathrm{E}$ where the three-phase outputs are on the top and two DC inputs are on the bottom (Figs. 5 and 6).

In between each pair of opposite devices an MKP capacitor is connected to improve the switching properties. The design was aimed to be very compact and in result the busbar width matches the width of the capacitors (apart from the copper area requirements). The distributed capacitors in the three phase legs are also supported by six main dc capacitors, i.e. $3 \times 20 \mu \mathrm{F}$ installed close to the dc inputs, and $3 \times 10 \mu \mathrm{F}$ placed on the top. In total, the dc capacitance equals $190 \mu \mathrm{F}$ which is a reasonable value when the inverter is loaded with R-L or pure inductive loads and operating at a switching frequency of $10 \mathrm{kHz}$. Actually, much lower values are possible in cases where no power feedback from the load is anticipated [35].

The heatsink assembly including power semiconductors, drivers, and dc capacitors is mounted inside the aluminum

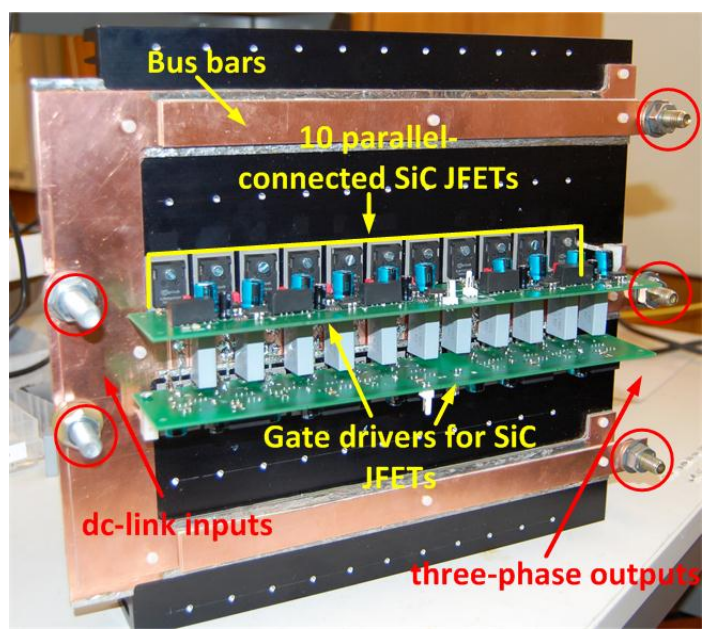

Fig. 5. Phase-leg with the PCBs of the gate drivers during the assembly process.

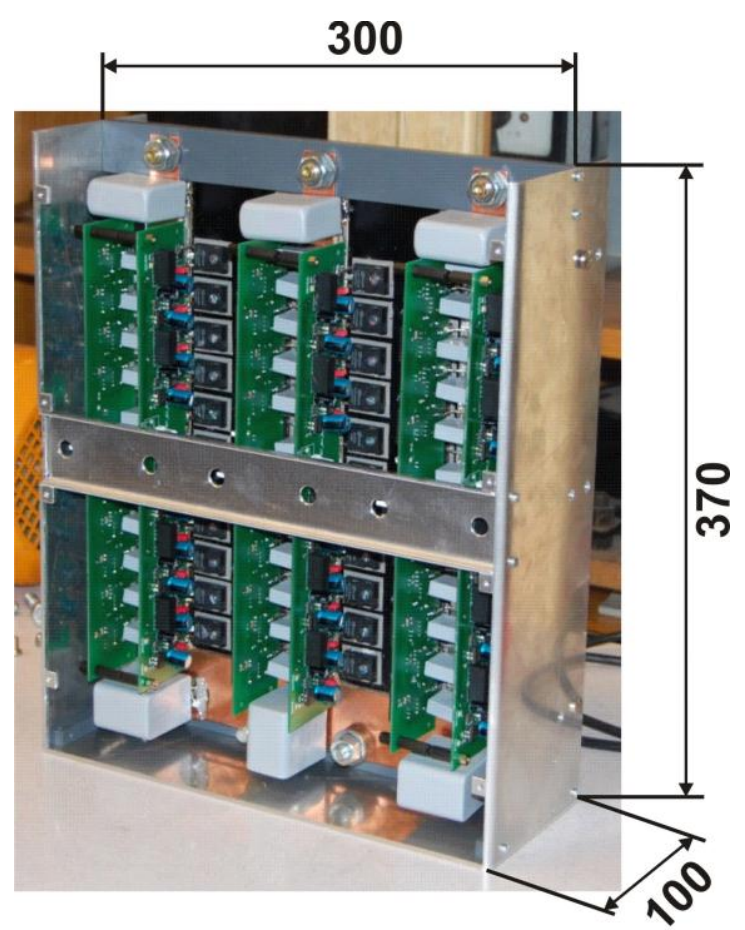

Fig. 6. Prototype of the SiC inverter (dimensions in $\mathrm{mm}$ ).

housing as can be seen in Fig. 6. The front is covered with a transparent plastic cover while the fins of the heat sink on the back are uncovered to permit free convection. Finally, the dimensions of the power circuit of the inverter including the gate-driver boards are 300x370x100 mm (volume $11.6 \mathrm{dm}^{3}$ ). With respect to the nominal power of $40 \mathrm{kVA}$, a power density of approximately $3.6 \mathrm{~kW} / \mathrm{dm}^{3}$ is obtained for the power circuit. There is no doubt that much higher power densities can be reached when $\mathrm{SiC}$ devices are packaged in a module [45]-[47]. 


\section{EXPERIMENTAL VERIFICATION}

The experimental verification of the $40 \mathrm{kVA} \mathrm{SiC}$ inverter was subdivided into two steps. First, the system was tested with reduced values of the input voltage and output current and all key quantities were observed in order to verify proper operation of the inverter. Measurements were conducted without any special protections against the normally-on characteristics of the JFETs because this issue was investigated as a separate part of the project. At this stage the inverter was loaded with an R-L load and the input and output powers were measured with an advanced power meter (see schematic in Fig.7) while the power was increased in small steps. At approximately half of the nominal power, the authors realized that accuracy of the electrical measurements was not sufficient in order to determine power losses in the range of 100-200 W. In the second step, therefore, an electro-thermal method was developed and applied to verify the remarkably low losses of the tested inverter. In order to limit the dissipated power in the laboratory, this part of the tests was performed with an inductive load.

\section{A. Test with inductive-resistive load up to $50 \%$ of nominal power}

Experiments have been performed on the three-phase $\mathrm{SiC}$ inverter using a setup shown in Fig. 7. The inverter was supplied from regulated direct voltage supply up to $700 \mathrm{~V}$ (DC generator) with special attention to precise power measurement of the input power. The load was composed of three $1 \mathrm{mH}$ air-cored inductors and adjustable power resistors. Current/voltage/power measurements were performed by means of a Yokogawa WT-3000 power meter. Steady-state operation of the inverter at $50 \%$ of the nominal load and switching frequency of $10 \mathrm{kHz}$ is illustrated in Fig. 8. The waveforms show a typical pulse-width modulation (PWM) output voltage and symmetrical output currents when the inverter feeds the R-L load and operates with an open-loop control. The power losses (Table I) were determined by subtracting the total output power from the input power. As the power meter was unable to measure the alternating output voltage with sufficient accuracy the voltage measurement was applied only across the adjustable resistors. In consequence, the loss amount $\Delta \mathrm{P}$, shown in the Table $\mathrm{I}$, besides semiconductor power losses contains also all types of inductor losses. Then, the winding losses in the inductors $\mathrm{P}_{\mathrm{RL}}$ were calculated using the RMS value of the output current and dc resistance of the inductors. Aiming for high accuracy, the dc resistance was measured at adequate winding temperatures with high current dc supply. Finally, from the obtained data it is clear that the efficiency at $50 \%$ load is at least $99.47 \%$. It

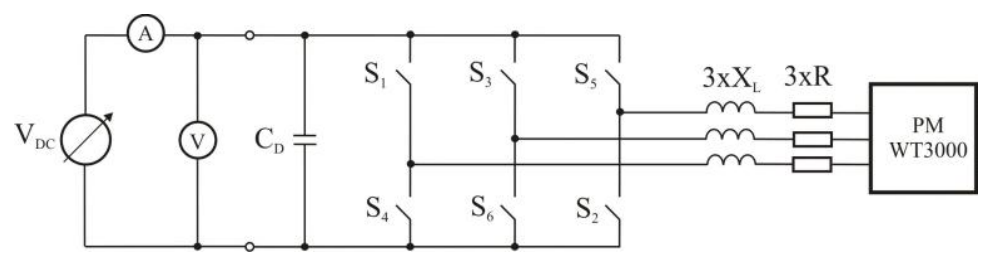

Fig. 7 Schematic of the experimental setup with RL load must be underlined that magnetic losses (caused by eddy currents in any metallic elements of the laboratory floor and additional losses in the windings) of the air-cored inductors are also included in the total the power loss value $(106 \mathrm{~W})$.

TABLE I. RESULTS OF ELECTRICAL MEASUREMENTS AT 50\% OF THE NOMINAL POWER WITH RL LOAD

\begin{tabular}{|l|l|l|l|l|l|l|}
\hline $\begin{array}{l}\mathrm{P}_{\mathrm{IN}} \\
{[\mathrm{W}]}\end{array}$ & $\begin{array}{l}\mathrm{P}_{\mathrm{OUT}} \\
{[\mathrm{W}]}\end{array}$ & $\begin{array}{l}\Delta \mathrm{P} \\
{[\mathrm{W}]}\end{array}$ & $\begin{array}{l}\mathrm{I}_{\mathrm{RMS}} \\
{[\mathrm{A}]}\end{array}$ & $\begin{array}{c}\mathrm{P}_{\mathrm{RL}} \\
{[\mathrm{W}]}\end{array}$ & $\begin{array}{l}\Delta \mathrm{P}-\mathrm{P}_{\mathrm{RL}} \\
{[\mathrm{W}]}\end{array}$ & $\begin{array}{l}\eta \\
{[\%]}\end{array}$ \\
\hline 20366 & 20099 & 267 & 29.1 & 160 & 106 & 99.47 \\
\hline
\end{tabular}

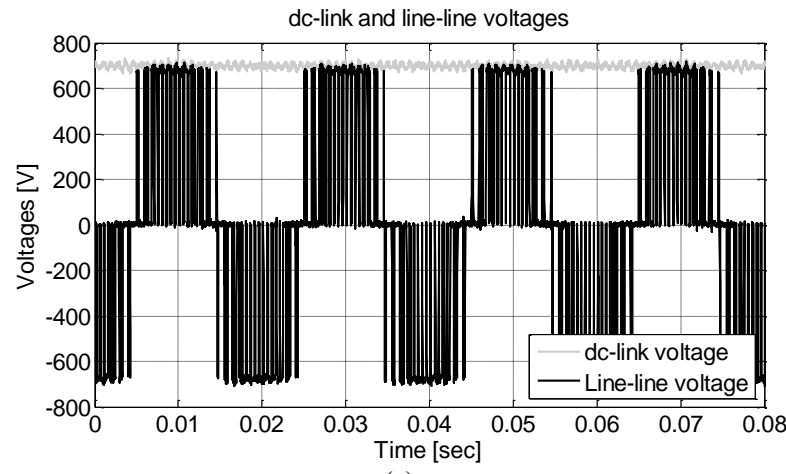

(a)

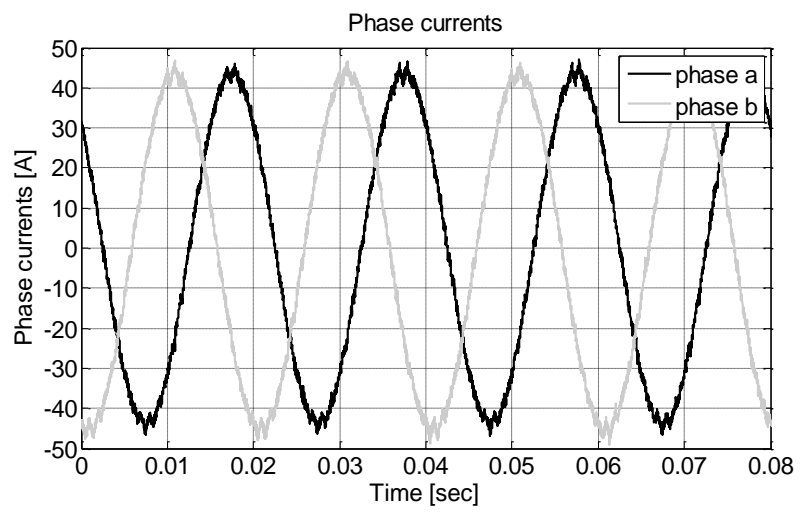

(b)

Fig. 8. Waveforms recorded during RL operation at $50 \%$ load

\section{B. Electro-thermal measurements}

Further improvements of the accuracy of the electrical measurement method were not realistic as they would require correct estimations of the magnetic losses of three air-cored inductors. Thus, the authors choose another possibility: a measurement method based on electro-thermal properties of the inverter.

The basic assumption of developed method is that the semiconductor power losses, despite of the type, either switching or conduction losses, result in the same temperature increase of the heatsink. This means that the junction temperature, or just the heat-sink temperature in steady-state, could be used as a non-electrical 
measurable quantity representing the magnitude of the power losses. Provided that a known reference case with a unique, precise, and reproducible relation between losses and temperature rise exists, the power losses occurring during inverter operation could be determined by comparison of the temperature rise in the reference case. Obviously, the characteristics of the average temperature of the heatsink $\mathrm{T}_{\mathrm{HAV}}$ as a function of heating power must be determined first. For maximum accuracy, the reference case was achieved by feeding direct current through all JFETs (see Fig. 9a) and measuring the temperature of the backside surface of the heatsink (see Fig. 9b), the direct current, and the voltage drop across the JFETs. In this way very accurate power measurements could be guaranteed at the same time as the loss distribution over the surface of the heat sink was the same as during normal operation. The total on-state resistance seen from the dc input was less than $10 \mathrm{~m} \Omega$. Thus, a high-current low-voltage regulated supply was required to reach ohmic power losses in the range of $100-200 \mathrm{~W}$. The $\mathrm{T}_{\mathrm{HAV}}$ is easily observed as the back of the inverter is open as can be seen in Figs. 5 and 6. From this point of view, power devices in discrete packages distributed among the heatsink surface can be recognized as an advantage (uniform heat distribution- see Fig.10).

The $40 \mathrm{kVA}$ SiC inverter model was characterized at various direct currents and power values where a typical heatup test took approximately $1.5 \mathrm{~h}$. Thermal camera images were recorded (see example in Fig. 9c) and analyzed every 5 minutes in order to ensure that steady-state conditions were established in each measurement cycle. Selected measurement data are collected in the Table II, where most of tests have been conducted for constant current. Because both the JFETs on-state resistance and the conduction losses change with temperature (almost double at $150^{\circ} \mathrm{C}$ compared to room temperature), the presented power value was averaged over measurement period. Due to the power variation additional tests with constant power were also performed (the direct current was continuously adjusted). The main part of the losses is caused by conduction and strongly depends on temperature. The second-most important part of the losses caused by switching - is almost temperature independent. This is why neither the constant direct current nor the constant dc power test could provide exactly the same conditions of heating-up process as occur during inverter operation. On the other hand, the main goal of the characterization was to find reasonable $\mathrm{T}_{\mathrm{HAV}}$ vs. $\mathrm{P}_{\mathrm{DC}}$ characteristics in steady-state, not to exactly reproduce the conditions of inverter operation.

A comparative nature of the electro-thermal method can be counted as an advantage when measurement errors are discussed. Most of the inaccuracies related to the heatsink temperature observation are cancelled when special attention is paid on keeping the same conditions during the tests (e.g. distance between the camera and the heatsink, lighting level in the room etc.). It is, therefore, two sources of the measurement error of the electro-thermal method left for further investigation. The first one is the error of the voltage and current measurements during direct current characterization tests (see Fig. 9a). The second one is related with the ambient temperature measurement. Finally it may be stated that the worst-case total measurement error is lower than $5 \%$.

The first results from the electro-thermal measurements were conducted at $50 \%$ of nominal power (the inverter was operating with R-L load as shown in Fig. 8). The result was significantly higher than the expectations (compared to the electrical measurements) as the obtained efficiency was $99.75 \%\left(\Delta \mathrm{T}=13^{\circ} \mathrm{C}\right)$.

TABLE II

DC CURRENT TEST RESULTS

\begin{tabular}{|c|c|c|c|}
\hline $\begin{array}{c}\text { No. of } \\
\text { test }\end{array}$ & $\begin{array}{c}\text { Current } \\
\text { conditions }\end{array}$ & $\begin{array}{c}\text { Power } \\
{[\mathrm{W}]}\end{array}$ & $\begin{array}{c}\text { Temperature rise, } \\
\Delta \mathrm{T}\left[{ }^{\circ} \mathrm{C}\right]\end{array}$ \\
\hline $\mathrm{DC} 1$ & $\mathrm{I}_{\mathrm{dc}}=80 \mathrm{~A}$ & 38.5 & 12 \\
\hline $\mathrm{DC} 2$ & $\mathrm{I}_{\mathrm{dc}}=120 \mathrm{~A}$ & 85.9 & 25.6 \\
\hline $\mathrm{DC} 3$ & Variable current & 100 & 28.3 \\
\hline DC4 & Variable current & 120 & 34.1 \\
\hline
\end{tabular}

\section{Pure inductive load test}

The final part of the measurements with full-power

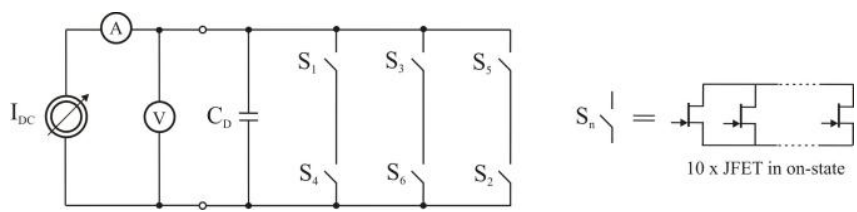

(a)

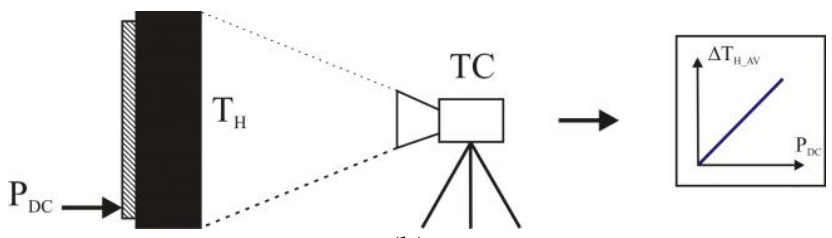

(b)

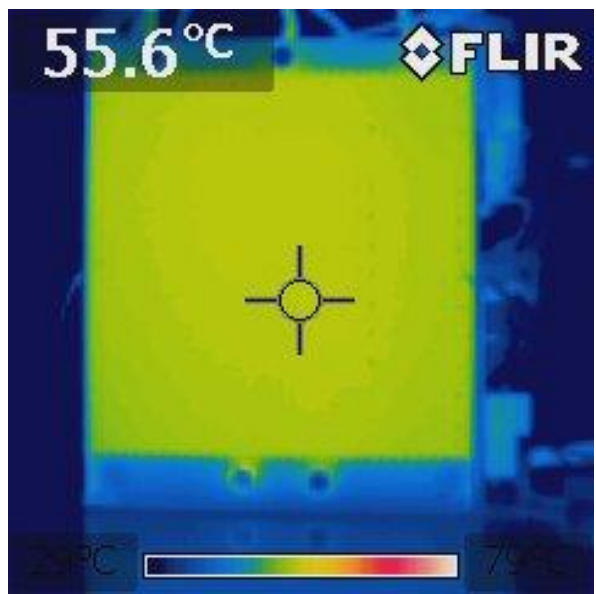

(c)

Fig. 9 Experimental setup for dc current characterisation: (a) electrical-circuit schematic, (b) measurement method and (c) thermal camera image of the backside of the heatsink 
inverter operation and recording of the heat sink temperature rise using thermal camera, was conducted using only inductive load (see Fig. 10). The reason for choosing this type of load was mainly to eliminate the great amount of heat dissipated at full load. During the single heat-up test (around $1.5 \mathrm{~h}$ ) the ambient temperature in the laboratory was rising by $2-3{ }^{\circ} \mathrm{C}$. Consequently, the thermal measurements were influenced already at the low power levels corresponding to the reference case. Tests with $40 \mathrm{~kW}$ power dissipation in the laboratory room would lead to much greater temperature rises and associated sources of errors in the measurements. Using only inductive load, the power losses transferred into heat were reduced to an acceptable level 1-2 kW. Therefore, the impact on the accuracy of the measurements was negligible. Thanks to reverse conduction of the SiC JFETs, the on-state power losses are independent on the power factor in contrast to IGBT inverters. That is why the behavior of the inverter operating at rated direct voltage and alternating current with pure inductive load is believed to be exactly the same as for any other type of load.

The schematic of the laboratory setup prepared for the pure inductive load test can be seen in Fig. 10a. The inverter was controlled with the use of standard Space-Vector PWM at $10 \mathrm{kHz}$ switching frequency and adjustable fundamental frequency. By changing the fundamental frequency different combinations of voltage and current as well reactive output powers could be obtained. Next Fig. 11 illustrates experimental waveforms at the rated output power. In spite of the low number of PWM pulses per period (visible in the output voltage), the load currents have almost sinusoidal waveforms. The main goal to run this test was to record the temperature of the heat sink in the steady-state case as is shown in Fig 10b. During the described tests the electrical measurements of input power and output current were conducted only as auxiliary variables enabling to detect an emergency situation.

\section{DISCUSSION OF RESULTS}

The goal of this project was to build and run the $40 \mathrm{kVA}$ inverter with parallel-connected SiC JFETs with only naturalconvection cooling. From the initial design process, an efficiency exceeding $99.5 \%$ was expected. Thus, a significant part of the laboratory work was concentrated on developing methods for efficiency measurements in order to guarantee a high accuracy.

The first sets of measurements were electrical measurements performed at half of the rated power employing a resistive-inductive load. Power losses of $106 \mathrm{~W}$ and a corresponding efficiency of $94.47 \%$ were recorded. At this point, it should be kept in mind that this number also includes high-frequency winding losses and magnetic losses of the aircore inductors.

In order to achieve a higher accuracy a special electrothermal measurement method was developed. The first set of these measurements were conducted at $50 \%$ of the rated power and by employing an R-L load. It was shown that the temperature rise of the heatsink corresponds to power losses of $50 \mathrm{~W}$ (efficiency of $99.75 \%$ ). Finally, an electro-thermal

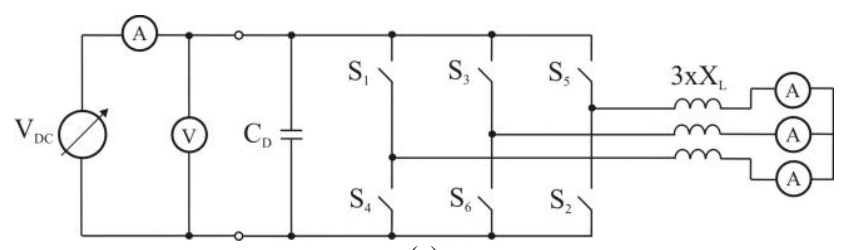

(a)

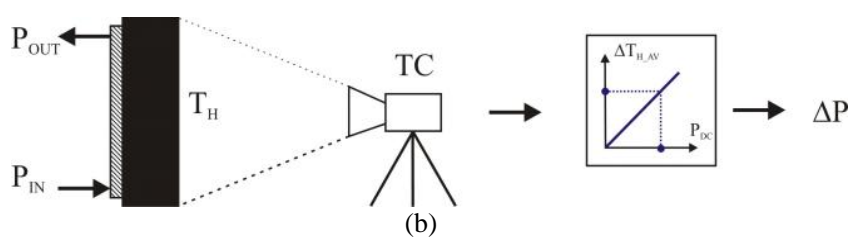

Fig. 10. Experimental setup for pure inductive test: (a) electrical schematic and (b) measurement method.

test was performed at the rated power and pure inductive load. A temperature rise of approximately $34{ }^{\circ} \mathrm{C}$ in the average temperature of the heatsink was observed, which corresponds to a dc power of $120 \mathrm{~W}$ (with an additional loss of $6 \mathrm{~W}$ in the worst case).

This number might be lower due to the contribution of the heat from the gate drivers in the average temperature rise of the heatsink. During normal operation at $10 \mathrm{kHz}$ switching frequency and when a typical Space Vector PWM signal was provided to the gates, the drivers approximately consume $24 \mathrm{~W}$. Another heat source was the dc supply (230 VAC / 24 VDC) mounted on the left side of the housing. On the other hand, during the direct current characterization, all JFETs were kept in the on-state and the gate drivers were not switching and their power consumption was quite low. This means that the influence of the additional heat sources was significantly lower in this case.

The amount of $24 \mathrm{~W}$ (measured at the input of common power supply, $4 \mathrm{~W}$ per switch position), is caused by the distributed PCB boards and the high number of sub-drivers employed. However, an optimal design of the gate-driver circuits might result in a lower power consumption. Finally, for this design $24 \mathrm{~W}$ is added to the semiconductor power loss resulting in total power losses of $144 \mathrm{~W}$ (or $150 \mathrm{~W}$ in the worst case).

There is no doubt that the electro-thermal method of efficiency estimation might be affected by various measurement errors. The authors believe that the main source of errors is the measurement of the dc power, while the measurement of the heatsink temperature was conducted under exactly the same conditions without significant changes in the system configuration. Therefore, if any errors had appeared they were cancelled by the comparative nature of the method.

Finally, it is believed that the measurement error of the applied measurement method was lower than 5\%, which is an extreme case. This means that even if the possible error is the worst one, the efficiency, including driving power, is still above $99.5 \%$ or more likely close to $99.6 \%$. 


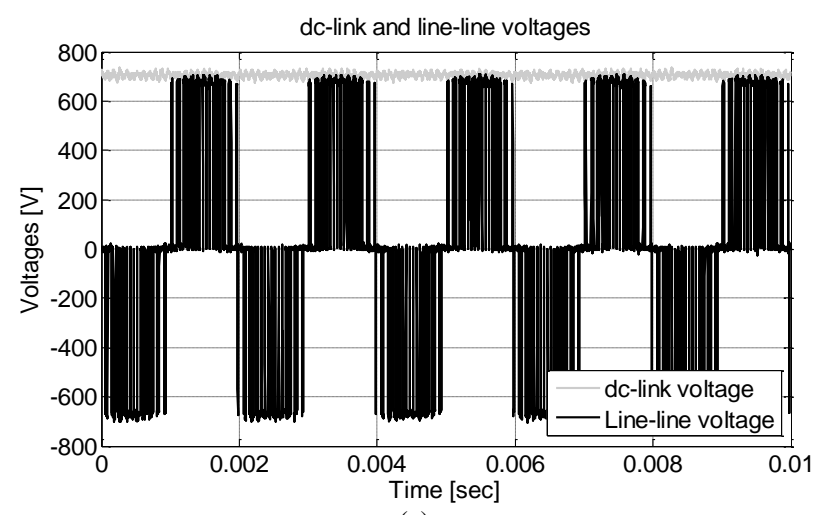

(a)

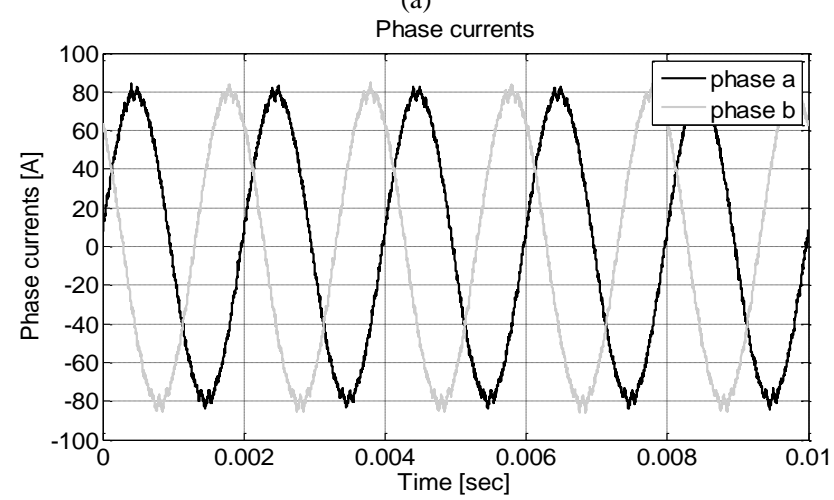

(b)

Fig. 11. Waveforms of the during pure inductive load test

\section{CONCLUSIONS}

In this paper a $40 \mathrm{kVA}$ three-phase $\mathrm{SiC}$ inverter having a remarkably high efficiency has been presented. The key to reach such high efficiencies is a combination of parallel connection of SiC JFETs, using the JFET also as an antiparallel diode, and a high switching speed. The on-state resistance of ten $\mathrm{SiC}$ JFETs operating in parallel for each switch position is close to $10 \mathrm{~m} \Omega$. Moreover, all devices switch fast.

The presented $40 \mathrm{kVA}$ inverter is designed to work with a natural-convection cooling only. Nevertheless, the size of the inverter is $11.6 \mathrm{dm}^{3}$ (power density of the power circuit $\sim 3.6$ $\left.\mathrm{kW} / \mathrm{dm}^{3}\right)$. The total cost of the applied $\mathrm{SiC}$ devices is approximately $1.5 \mathrm{kUSD}$, which corresponds to 37.5 $\mathrm{USD} / \mathrm{kW}$, where $17.5 \mathrm{USD} / \mathrm{kW}$ can be distinguished as the additional cost to reach the very high efficiency. As the SiC transistors are still not massively produced, the comparable $40 \mathrm{kVA}$ inverter built with state-of-the-art Si IGBTs offer much lower devices cost. Depending on the IGBT module performance the cost is approximately 4-6 USD/kW [48].

Various electrical and thermal measurements have been performed at different power levels in order to verify the low power losses. Most of the losses are caused by conduction of the SiC JFETs. The total losses were found to be $144 \mathrm{~W}$ at nominal conditions, of which $24 \mathrm{~W}$ is the power consumption of the gate drivers. Even if the maximum possible measurement error of $5 \%$ is assumed for the applied electrothermal method the overall efficiency exceeds $99.5 \%$. The semiconductor power losses of a comparable $40 \mathrm{kVA}$ inverter built with state-of-the-art $\mathrm{Si}$ IGBTs having a switching frequency of $10 \mathrm{kHz}$ are at least $430 \mathrm{~W}$ [49]. Finally, the total efficiency of the $\mathrm{Si}$ inverter is in the range of $98.5 \%$.

\section{REFERENCES}

[1] Bose B.K., Power Electronics and Motor Drives - Recent Progress and Perspective, IEEE Transactions on Industrial Electronics, Vol.ume: 56, Issue: 2, 2009 , pp. $581-588$

[2] Abrahamsen F., Blaabjerg F., Pedersen J.K., Thoegersen P.B., "Efficiency-optimized control of medium-size induction motor drives", IEEE Transactions on Industry Applications, Vol. 37, Issue: 6, 2001, pp. $1761-1767$

[3] Rooks J.A., Wallace A.K, "Energy efficiency of VSDs", IEEE Industry Applications Magazine, Vol. 10, Issue 3, 2004, pp. 51-67

[4] Aníbal T. de Almeida, Fernando J. T. E. Ferreira, and Dick Both, "Technical and Economical Considerations in the Application of Variable-Speed Drives With Electric Motor Systems", IEEE Transactions on Industry Applications, vol. 41, no. 1, 2005, pp. 188199.

[5] Kazmierkowski M.P., Franquelo L.G., Rodriguez J., Perez M.A., Leon J.I., "High-Performance Motor Drives", IEEE Industrial Electronics Magazine, Vol. 5, Issue: 3, 2011 , pp. 6-26

[6] Hiller M., Sommer R., Beuermann M., "Medium-Voltage Drives", IEEE Industry Applications Magazine, Vol. 16, Issue 2, 2010, pp. 22 30

[7] Johnson R.W., Bromstead J.R., Weir G.B.,200 ${ }^{\circ} \mathrm{C}$ operation of semiconductor power devices, IEEE Transactions on Components, Hybrids, and Manufacturing Technology, Vol. 16 , Issue: 7, 1993, pp. $759-764$

[8] Xu, Zhuxian; Jiang, Dong; Li, Ming; Ning, Puqi; Wang, Fred; Liang, Zhenxian, "Si IGBT phase-leg module packaging and cooling design for operation at $200{ }^{\circ} \mathrm{C}$ in hybrid electrical vehicle applications", Twenty-Seventh Annual IEEE Applied Power Electronics Conference and Exposition (APEC), 2012, pp. $483-490$

[9] Biela, J.; Schweizer, M.; Waffler, S.; Kolar, J.W.,SiC versus SiEvaluation of Potentials for Performance Improvement of Inverter and DC-DC Converter Systems by $\mathrm{SiC}$ Power Semiconductors, IEEE Transactions on Industrial Electronics, Vol. 58, Issue 7, 2011, pp. 2872 $-2882$

[10] B. Burger, D. Kranzer, "Extreme high efficiency PV-power converters,", in Proc. 13th European Conference on Power Electronics and Applications, 2009. EPE '09., 8-10 Sept. 2009, pp. 1-13.

[11] C. Wilhelm, D. Kranzer, and B. Burger, "Development of a highly compact and efficient solar inverter with Silicon Carbide transistors," in Proc. 6th International Conference on Integrated Power Electronics Systems (CIPS), 2010, 16-18 March 2010, pp. 1-6.

[12] Hui Zhang, L.M. Tolbert, and B. Ozpineci, "Impact of SiC Devices on Hybrid Electric and Plug-In Hybrid Electric Vehicles," IEEE Transactions on Industry Applications, vol. 47, no. 2, March-April 2011, pp. 912-921.

[13] A. Antonopoulos, H. Bangtsson, M. Alakula, and S. Manias, "Introducing a silicon carbide inverter for hybrid electric vehicles," in Proc. IEEE Power Electronics Specialists Conference, 2008, PESC 2008, 15-19 June 2008, pp. 1321-1325.

[14] G. Roberts, A.T. Bryant, P.A. Mawby, T. Ueta, T. Nisijima, and K. Hamada, "Evaluation of silicon carbide devices for hybrid vehicle drives," in Proc. European Conference on Power Electronics and Applications, 2007, 2-5 Sept. 2007, pp. 1-10.

[15] K. Acharya, S.K. Mazumder, and P. Jedraszczak, "Efficient, HighTemperature Bidirectional Dc/Dc Converter for Plug-in-Hybrid Electric Vehicle (PHEV) using SiC Devices," in Proc. Twenty-Fourth Annual IEEE Applied Power Electronics Conference and Exposition, 2009, APEC 2009, 15-19 Feb. 2009, pp. 642-648. 
[16] B. Wrzecionko, J. Biela, and J.W. Kolar, "SiC power semiconductors in HEVs: Influence of junction temperature on power density, chip utilization and efficiency," in Proc. 35th Annual Conference of IEEE Industrial Electronics, 2009, IECON '09, 3-5 Nov. 2009, pp. 38343841.

[17] D. Peftitsis, G. Tolstoy, A. Antonopoulos, J. Rabkowski, J.-K. Lim, M. Bakowski, L. Angquist, and H.-P. Nee, "High-power modular multilevel converters with SiC JFETs," IEEE Transactions on Power Electronics, Vol. 27, Issue 1, 2012, pp. 28-36.

[18] M. Chinthavali, P. Ning, Y. Cui, and L.M. Tolbert, "Investigation on the parallel operation of discrete SiC BJTs and JFETs," in Proc. 2011 Twenty-Sixth Annual IEEE Applied Power Electronics Conference and Exposition (APEC), 6-11 March 2011, pp. 1076-1083.

[19] D. Peftitsis, R. Baburske, J. Rabkowski, J. Lutz, G. Tolstoy, and H.-P. Nee, "Challenges regarding parallel-connection of SiC JFETs," IEEE Transactions on Power Electronics, (early access).

[20] F. Xu, D. Jiang, J. Wang, F. Wang, L.M. Tolbert, T.J. Han, J. Nagashima, S.J. Kim, "High temperature packaging of $50 \mathrm{~kW}$ threephase SiC power module" in Proc. 2011 IEEE 8th International Conference on Power Electronics and ECCE Asia (ICPE \& ECCE), May 30 2011-June 3 2011, pp .2427-2433.

[21] Palmer M.J., Johnson R.W., Autry T., Aguirre R., Lee V., Scofield J.D., "Silicon Carbide Power Modules for High-Temperature Applications", IEEE Transactions on Components, Packaging and Manufacturing Technology, Volume: 2, Issue: 2, 2012 , pp. 208 - 216

[22] Rixin Lai, Fei Wang, Burgos R., Boroyevich D., Di Zhang, Puqi Ning, "A Shoot-Through Protection Scheme for Converters Built With SiC JFETs", IEEE Transactions on Industry Applications, vol. 46, no. 6, 2010, pp. 2495-2500.

[23] H.-S. Lee, M. Domeij, C.-M. Zetterling, R. Ghandi, M. Ostling, F. Allerstam, and E. O. Sveinbjornsson, "1200 V 4H-SiC BJTs with a Common Emitter Current Gain of 60 and Low On-resistance," in Proc. International Conference on SiC and Related Materials 2007 (ICSCRM 2007), Lake Biwa Resort, Otsu, Japan, October 14 - 19, 2007.

[24] M. Treu, R. Rupp, P. Blaschitz, K. Ruschenschmidt, T. Sekinger, P. Friedrichs, R. Elpelt, and D. Peters, "Strategic Considerations for Unipolar SiC Switch Options: JFET vs. MOSFET," in Proc. 2007 IEEE Industry Applications Conference, 23-27 Sept. 2007, pp. 324-330.

[25] Rixin Lai, Wang F., Puqi Ning, Di Zhang, Dong Jiang, Burgos R., Boroyevich D., Karimi K.J., Immanuel V.D., "A High-Power-Density Converter", IEEE Industrial Electronics Magazine, Volume: 4 , Issue: 4, 2010 , pp. $4-12$

[26] Friedli T., Round S.D., Hassler D., Kolar J.W., "Design and Performance of a $200-\mathrm{kHz}$ All-SiC JFET Current DC-Link Back-toBack Converter", IEEE Transactions on Industry Applications, Vol. 45, Issue: 5, 2009, pp. 1868-1878

[27] Jun Wang, Xiaohu Zhou, Jun Li, Tiefu Zhao, Huang A.Q., Callanan R., Husna F., Agarwal A., "10-kV SiC MOSFET-Based Boost Converter", IEEE Transactions on Industry Applications, Vol. 45 , Issue: 6, 2009, pp. 2056 - 2063

[28] S. Round, M. Heldwein, J. Kolar, I. Hofsajer, and P. Friedrichs, "A SiC JFET driver for a $5 \mathrm{~kW}, 150 \mathrm{kHz}$ three-phase PWM converter," in Proc. 2005 IEEE Industry Applications Conference, 2-6 Oct. 2005, pp. 410- 416.

[29] J. Callaway, Y. Wang, R. Burgos, T.P. Chow, F. Wang, and D. Boroyevich, "Evaluation of SiC JFETs for a Three-Phase CurrentSource Rectifier with High Switching Frequency", in Proc. Twenty Second Annual IEEE Applied Power Electronics Conference, APEC 2007, pp. $345-351$.

[30] Kelley R., Ritenour A., Sheridan D., Casady J., "Improved two-stage DC-coupled gate driver for enhancement-mode SiC JFET", in Proc. Twenty-Fifth Annual IEEE Applied Power Electronics Conference and Exposition (APEC), 2010 , pp. 1838 - 1841.

[31] Wrzecionko, B., Kach S., Bortis D., Biela J., Kolar J.W., "Novel AC coupled gate driver for ultra fast switching of normally-off SiC JFETs," 36th Annual Conference on IEEE Industrial Electronics Society IECON 2010, pp.605-612
[32] J. Rabkowski, G. Tolstoy, D. Peftitsis, H.P. Nee, Low-Loss HighPerformance Base-Drive Unit for SiC BJTs, IEEE Transaction on Power Electronics, Vol. 27, Issue 5, 2012, pp. 2633-2433

[33] P. Friedrichs and R. Rupp, "Silicon carbide power devices - current developments and potential applications," in Proc. 2005 European Conference on Power Electronics and Applications, EPE 2005.

[34] J.B. Casady, D.C. Sheridan, R. Kelley, V. Bondarenko, A. Ritenour, "A comparison of $1200 \mathrm{~V}$ Normally-Off \& Normally-On Vertical Trench SiC Power JFET Devices," Material Science Forum Vols. 679-680, 2011, pp. 641-644.

[35] K. Kretschmar and H.-P. Nee, "An AC Converter with a Small DC link Capacitor for a $15 \mathrm{~kW}$ Permanent Magnet Synchronous Integral Motor," in Proc. of the Seventh International Conference on Power Electronics and Variable Speed Drives 1998, PEVD '98, Sept. 1998, pp. 622-625.

[36] Weis B., Peters D., Wölz M., ,A new 690V AC drive with integrated sine wave output filter and SiC schottky freewheeling diodes", Proceedings SPS/IPC/DRIVES 2006, VDEVerlag, Berlin 2006, p. 159 168

[37] R. Siemieniec and U. Kirchner, "The $1200 \mathrm{~V}$ direct-driven SiC JFET power switch," Proc. of the 2011-14th European Conference on Power Electronics and Applications, EPE 2011

[38] K. Norling; C. Lindholm; D. Draxelmayr; , "An optimized driver for SiC JFET-based switches delivering more than $99 \%$ efficiency," IEEE International Solid-State Circuits Conference Digest of Technical Papers (ISSCC), 2012, pp.284-286, 19-23 Feb. 2012B

[39] Dubois, D. Bergogne, D. Risaletto, R. Perrin, A. Zaoui, H. Morel, and R Meuret, "Ultrafast Safety System to Turn-Off Normally On SiC JFETs," Proc. of the 2011-14th European Conference on Power Electronics and Applications, EPE

[40] D. Bergogne; D. Risaletto; F. Dubois; A. Hammoud; H. Morel; P. Bevilacqua; B. Allard; O. Berry; F. Meibody-Tabar; S. Raeel; R. Meuret; S. Dhokkar; Hispano-Suiza; , "Normally-On SiC JFETs in power converters: Gate driver and safe operation," 6th International Conference on Integrated Power Electronics Systems (CIPS), 2010, pp.1-6, 16-18 March 2010

[41] F. Guédon; S.K. Singh; R.A. McMahon; F. Udrea; , "Gate driver for $\mathrm{SiC}$ JFETs with protection against normally-on behaviour induced fault," Electronics Letters, vol.47, no.6, pp.375-377, March 172011

[42] L. Rixin; W. Fei; R. Burgos; D. Boroyevich; Di Zhang; Puqi Ning; , "A Shoot-Through Protection Scheme for Converters Built With SiC JFETs," IEEE Transactions on Industry Applications, vol.46, no.6, pp.2495-2500, Nov.-Dec. 2010

[43] Jong-Hyun Kim; Byung-Duk Min; Ju-Won Baek; Dong-Wook Yoo; , "Protection circuit of normally-on SiC JFET using an inrush current," 31st International Telecommunications Energy Conference, 2009. INTELEC 2009, pp.1-4, 18-22 Oct. 2009

[44] D. Peftitsis, J. Rabkowski and H.-P. Nee, "Self-Powered Gate Driver for Normally-ON Silicon Carbide Junction Field-Effect Transistors Without External Power Supply", accepted for publication in IEEE Trans. On Power Electronics.

[45] L. De Lillo, L. Empringham, M. Schultz and P. Wheeler, „A high power density SiC-JFET-based matrix converter" in Proc. Of EPE 2011.

[46] Takao, K.; Shinohe, T., "Demostration of $25 \mathrm{~W} / \mathrm{cm} 3$ class all-SiC three phase inverter", in Proc. Of EPE 2011

[47] Wrzecionko, B.; Biela, J.; Kolar, J.W., "SiC power semiconductors in HEVs: Influence of junction temperature on power density, chip utilization and efficiency", 35th Annual Conference of IEEE Inductrial Electronics, IECON 2009 , pp. 3834 - 3841

[48] www.findchips.com

[49] IPOSIM: Power Module Selector and Simator at www.infineon.com 